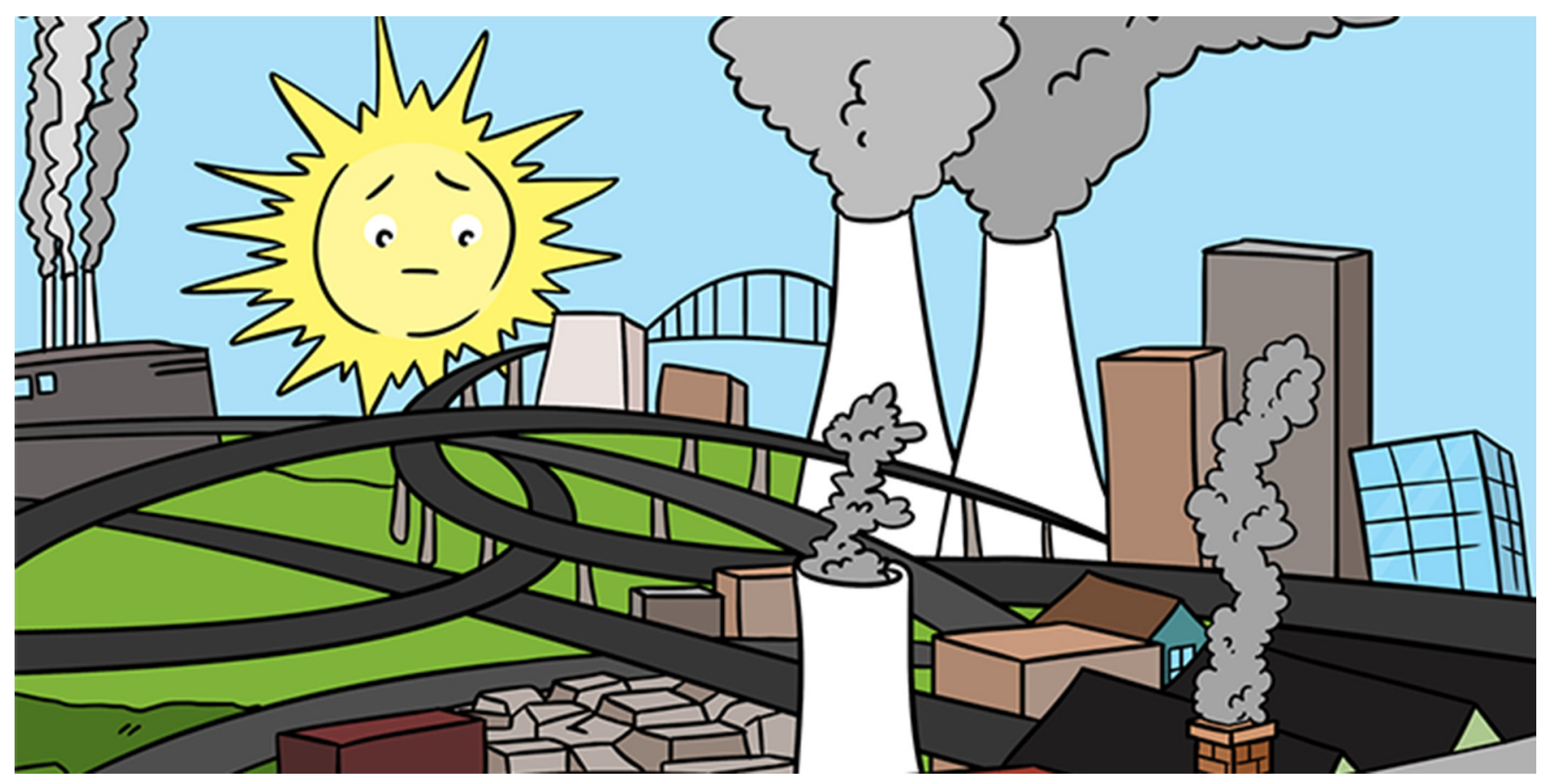

\title{
CONVERTING SUNLIGHT INTO FUEL USING A UNIQUE MINIATURE SYSTEM
}

\section{Lilac Amirav *}

Schulich Faculty of Chemistry, Technion-Israel Institute of Technology, Haifa, Israel

YOUNG REVIEWER:

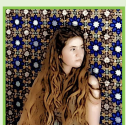

ANNA

AGE:13
The world's increasing need for energy, along with the alarming consequences of burning fossil fuels (such as oil, coal, or natural gas) in power plants and vehicles, make the search for alternative energy sources vital for the future of the planet. Solar-driven splitting of water into hydrogen and oxygen is a potential source of clean and renewable fuel. In this article, I describe and explain how this can be accomplished by a process called photocatalysis, and how we were able to obtain an efficient conversion of light into hydrogen using a unique miniature system.

\section{THE ENERGY PROBLEM}

Shalev just turned 9 years old. When he was born, in December of 2010, there were 6.9 billion ( 1 billion $=1,000,000,000$ ) people in our world. Now there are 7.8 billion. It is projected that, by the time Shalev becomes a dad, his kids will share the world with over 9.6 billion people. As the world population is growing, so is our need for energy. 
Have you ever stopped to consider how much energy you are using every day? We use energy while watching TV, cooking dinner, lighting our rooms at night, warming our homes during the cold winter, and even driving our cars.

So, how much energy are we using? The total energy used by all of human civilization increased from about one terawatt in 1890 to 19.4 terawatts last year [1]. To be clear, 1 terawatt (TW) is one trillion (10 ${ }^{12}$ ) watts, and is equivalent to 5 billion barrels of oil, or 1 billion tons of coal! It is anticipated that, by 2040, the world's energy consumption will increase by another $48 \%$. This will result in a 10 TW gap between the amount of energy we are currently capable of producing each year and what we expect to use 20-30 years from now. How will we ever bridge that gap? This problem gets even more challenging because most of our energy comes from resources that are being used up, such as oil (which contributes $33 \%$ of the world's energy), coal (30\%), and natural gas (24\%), which are often referred to as fossil fuels. We are depleting these resources because they are produced by nature much more slowly than we are using them up. For example, most of the oil deposits existing today were formed about 250 million years ago, from tiny plants and animals called algae and plankton. Dead plankton and algae sank to the bottom of an ancient ocean and mixed with sand and other sediment, in an environment without oxygen. This created an organic-rich mud that was buried and covered by more sediment over

THE GREENHOUSE EFFECT

The greenhouse effect is a natural process that warms the Earth's surface (and the air above it), due to trapping of sun's energy by gases in the atmosphere. When the sun's energy reaches the Earth's atmosphere some of it is reflected back to space and the rest is absorbed and re-radiated by greenhouse gases. These heat trapping gases act like the walls and roof of an agricultural greenhouse. Without the greenhouse effect, Earth would be too cold for life to exist. Yet, industrial production of greenhouse gases is now casing a raise in temperature. the course of many years. Due to increased pressure and temperature, this mud eventually transformed into oil.

We must prepare for the inevitable depletion of fossil fuel supplies, because without these energy sources our entire way of life will change. In addition, the pollution from burning fossil fuels is disastrous, causing global warming, and other climate changes due to the greenhouse effect. Pollution also directly kills many people. In China, it is estimated that 1.6 million people die each year from breathing polluted air. So, in order to meet the increasing global demand for energy and to protect our environment, alternative "clean" energy sources must be developed.

\section{SOLAR ENERGY AS A SOLUTION}

While we contemplate on these glooming prospects, let us look at the bright side-up toward the sky. Every day, the sun sends out an enormous amount of energy. The amount of solar energy reaching the surface of our planet is so vast that in 1 year it is about twice as much as will ever be obtained from all of the Earth's non-renewable resources of coal, oil, natural gas, and mined uranium (for nuclear energy) combined. The sun provides more energy in about an hour than the world uses in one year! Furthermore, the sun is free and does not belong to any one country. It is a local, inexhaustible resource that is clean and sustainable. 
PHOTOSYNTHESIS

A process used by plants and other organisms to convert light into the type of fuel needed by the organism, such as sugars. Using light, sugars are made from carbon dioxide and water.

\section{PHOTOCATALYSIS}

The word is composed of two parts. The prefix "photo" means light. "Catalysis" refers to a process in which a substance (called a catalyst) speeds up the rate of a chemical reaction without being altered or used up. In a photocatalytic reaction, the catalyst is activated by light.
Tremendous effort is going into the development of means to capture the sun's energy, with focus on various types of solar cells. The disadvantage of solar cells is that they provide energy in the form of electricity, which cannot satisfy all of our society's energy needs. We also do not want to depend on an energy source that is only available on sunny days, which is the only time solar cells can work well. Not surprisingly, nature found a solution with an alternative way to use solar energy: plants use it in the process of photosynthesis, converting light into fuel for the plant. It is much easier to store fuel in comparison to storing electricity or heat. Nature may serve as our inspiration for the development of an artificial photosynthetic system, in which solar energy is converted directly into a fuel that can be easily stored and transported, based on a process called photocatalysis.

\section{PHOTOCATALYTIC SYSTEMS}

Photocatalytic systems are typically made of materials called semiconductors. Semiconductors are employed in solar cells, and are also the foundation of modern electronics. A semiconductor is a substance that can conduct electricity under some conditions but not others. When a semiconductor absorbs light, the energy stored in the light is converted to the generation of negative and positive charges within the material, as illustrated in Figure 1 (step 1). In solar cells these charges are being utilized directly as current (electricity). In photocatalysis however, these charges are used for the promotion of a type of chemical reactions, called oxidation-reduction, that involve transfer of charges between species. In addition, photocatalytic systems often include small metallic particles (illustrated in purple in Figure 1) that help improve the rate of the reaction. Briefly, a photocatalytic system absorbs light, and converts the solar energy into positive and negative electric charges which are then used to promote chemical reactions of interest.

\section{CONVERTING SOLAR ENERGY INTO FUEL WITH PHOTOCATALYTIC SYSTEMS}

We would like to use the electric charges generated by a photocatalytic system to assist chemical reactions that would result in the formation of fuel. We define fuel as a chemical substance that provides energy when burned (combined with oxygen). Some reactions require energy to proceed, while others release energy. Our goal is to find a chemical reaction that requires energy, and use the sun's power to promote that reaction. In the course of that reaction chemical bonds are broken, other bonds are formed, and new molecules are created. Then, the reverse reaction could release the energy, which is stored in the chemical bonds of the product molecules, upon demand, whenever we wanted it to.

Next, we need to determine what type of fuel to make, and which molecule to break down with the sun's energy for the production of 


\section{Figure 1}

The photocatalytic process. Step 1: upon light absorption by a semiconductor photocatalyst (yellow), a negative charge and a positive charge are formed. In step 2 these charges promote the chemical reaction, splitting water into oxygen and hydrogen.

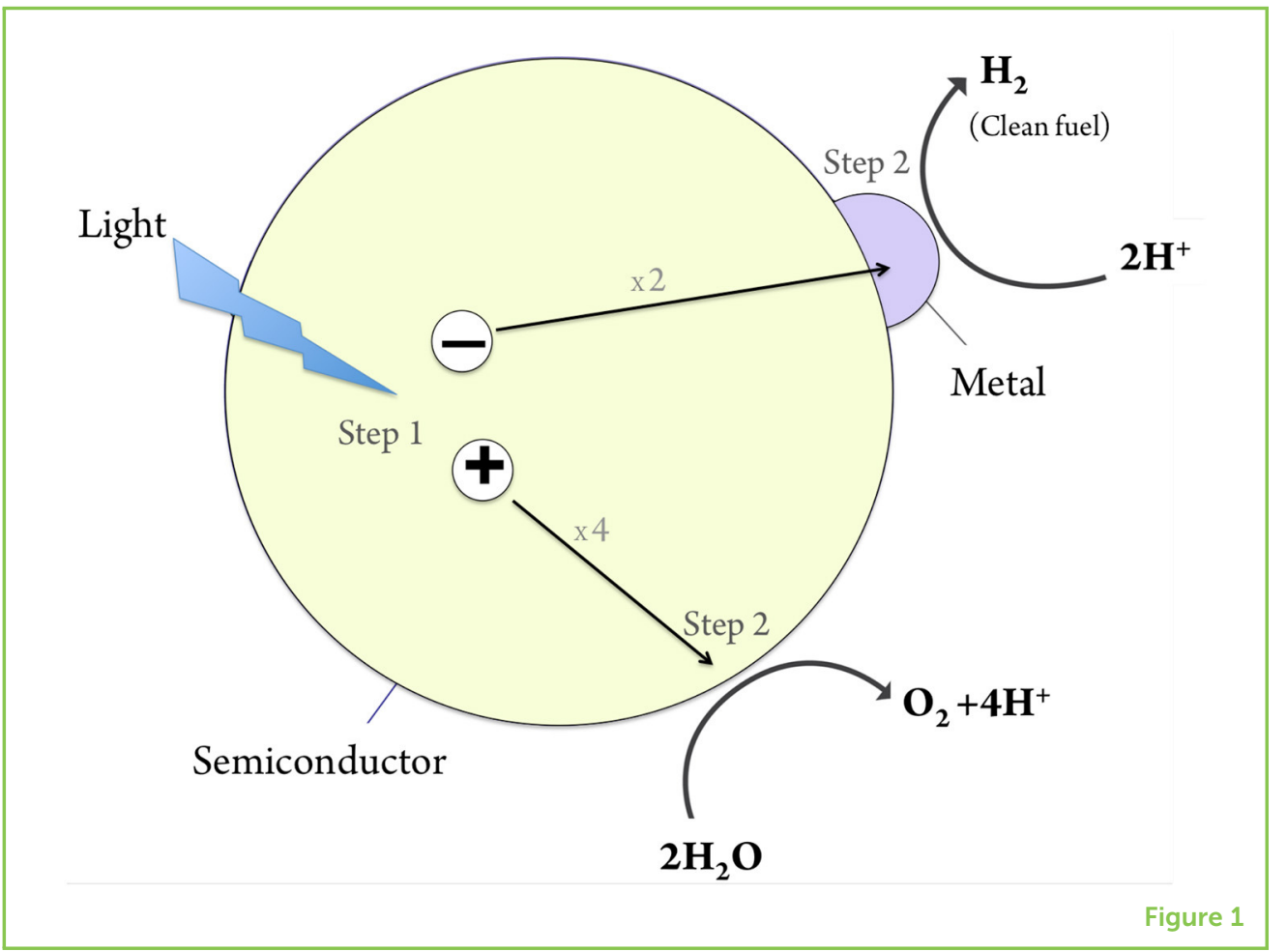

the fuel. Think of something that we have a lot of on earth, something simple and renewable. If you guessed water, you guessed correctly. In fact, the idea of using water and light for energy production has existed for quite some time. "Water will be the coal of the future," wrote Jules Verne, in The Mysterious Island, back in 1874. Both sunlight and water are easy to acquire and found almost everywhere on earth. We decided to use sunlight to split water for the production of oxygen and hydrogen molecules. Hydrogen can then be used as fuel. Unlike fossil fuels, hydrogen is a pollution-free source of energy. When hydrogen is burned, meaning when it reacts with oxygen, only water and energy are produced. Hydrogen also serves chemists for production of ammonia, an important fertilizer that is vital for agriculture.

Despite the great potential, after four decades of global research, stable and efficient photocatalytic systems have still not been developed, because the process is complicated and there are many challenges still to be faced. For example, if the positive and negative charges, which are attracted to one another, manage to recombine, they cancel each other and the energy is lost. To make progress, our research group and others have been studying simpler forms of photocatalytic reactions, focusing only on reactions that involve one type of charges, hoping that these simpler forms will eventually help us to understand the full process and produce efficient photocatalytic systems. This is carried out through the use of chemical additives that cancel the unwanted charges. 
Figure 2

Artistic illustration of the nanoscale photocatalysts, which are composed of a tiny spherical nano-sized particle of one material (green), embedded within a second material that is rod-shaped (yellow), with a platinum particle at its tip (purple). The structure of this photocatalyst separates the negative and positive charges, which is the key to the success of the system.

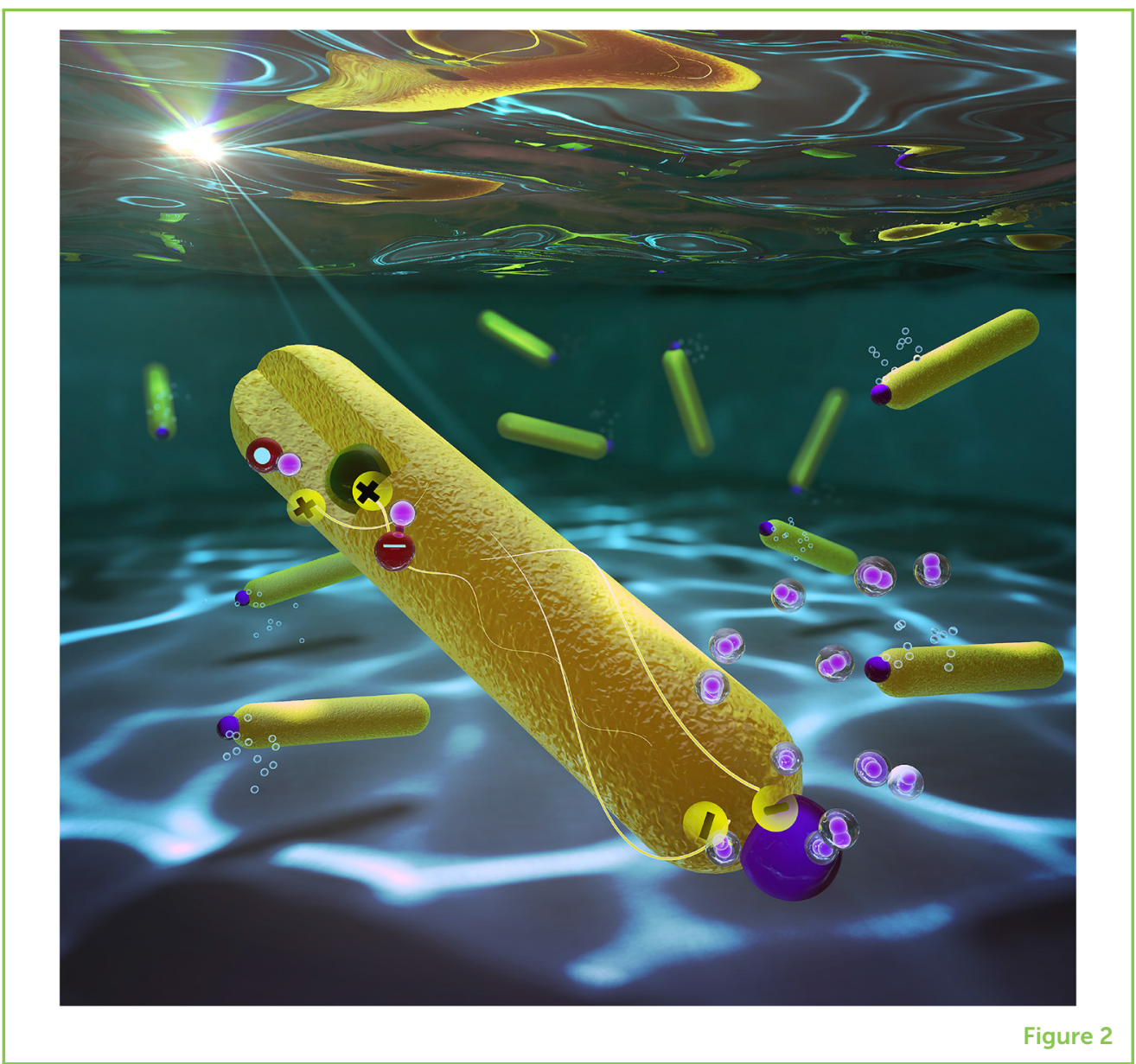

\section{OUR SUCCESS AND THE NEXT CHALLENGES}

Recently, our research group achieved nearly perfect conversion of light into hydrogen molecules [2]. This means that all of the light that shined upon the photocatalyst successfully produced hydrogen from water. This impressive efficiency was accomplished by using a unique miniature photocatalysts, with dimensions on the nanometer range. One nanometer $(\mathrm{nm})$ is $10^{-9} \mathrm{~m}$. To put this size into perspective, the diameter of a human hair is about $50,000 \mathrm{~nm}$. A fascinating and powerful outcome of working with nanoscale particles is the size-dependent tunability of their properties. By changing the size of the particle, a scientist can fine-tune a property of interest, such as what color of light will be absorbed by the semiconductor, and possibly make it a better photocatalyst.

The system we developed is illustrated in Figure 2. It consists of two semiconductors, a tiny spherical nano-sized particle made of a material called cadmium selenide, embedded within a second material that is rod-shaped (cadmium sulfide), with a platinum metallic particle at its tip. The spherical particle attracts positive charges, while negative charges accumulate on the platinum tip. The good separation between these charges is the key to the success of the 
system [3]. It prevents the negative charges, which are responsible for the reaction that produces hydrogen from water, from being canceled by the positive charges. Because our system is so efficient, a single photocatalyst nanoparticle can produce 360,000 molecules of hydrogen per hour! This is the highest efficiency ever reported for this kind of system.

While our nanoscale photocatalyst was found to be efficient for hydrogen production, it is not suitable for overall water splitting, because it is not stable enough. Prolonged exposure to light leads to breakdown of the materials that make up the photocatalyst. Because we would have to continuously add some additional chemicals to prevent this breakdown, we would not truly be producing energy with this system.

Our achievement is a significant milestone, yet the road toward direct and genuine conversion of solar energy into fuel is still long. Perhaps one day YOU will be the one who will develop a system that works.

\section{ACKNOWLEDGEMENTS}

This research was carried out in the framework of the Russell Berrie Nanotechnology Institute (RBNI) and the Nancy and Stephen Grand Technion Energy Program (GTEP).

\section{REFERENCES}

1. According to the U.S Energy Information Administration.

2. Kalisman, P., Nakibli, Y., and Amirav, L. 2016. Perfect photon-to-hydrogen conversion efficiency. Nano Lett. 16:1776-81. doi: 10.1021/acs.nanolett.5b 04813

3. Amirav, L., and Paul, A. A. 2010. Photocatalytic hydrogen production with tunable nanorod heterostructures. J Phys Chem Lett. 1:1051-4. doi: 10.1021/jz100075c

SUBMITTED: 06 February 2020; ACCEPTED: 13 March 2020;

PUBLISHED ONLINE: 23 April 2020.

EDITED BY: Idan Segev, Hebrew University of Jerusalem, Israel

CITATION: Amirav L (2020) Converting Sunlight Into Fuel Using a Unique Miniature System. Front. Young Minds 8:39. doi: 10.3389/frym.2020.00039

CONFLICT OF INTEREST: The author declares that the research was conducted in the absence of any commercial or financial relationships that could be construed as a potential conflict of interest. 
COPYRIGHT @ 2020 Amirav. This is an open-access article distributed under the terms of the Creative Commons Attribution License (CC BY). The use, distribution or reproduction in other forums is permitted, provided the original author(s) and the copyright owner(s) are credited and that the original publication in this journal is cited, in accordance with accepted academic practice. No use, distribution or reproduction is permitted which does not comply with these terms.

\section{YOUNG REVIEWER}

\section{ANNA, AGE: 13}

I am 13 years old. I love arts especially drawing. I love spending time with my friends and family and I have a dog and I love it very much. I find science and biology in particle, very interesting.

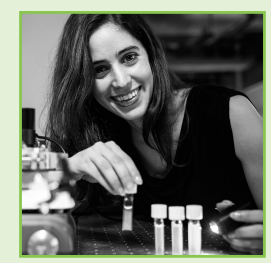

\section{AUTHOR}

\section{LILAC AMIRAV}

I am a Professor at the Technion-Israel Institute of Technology, where I lead the "photocatalysis on the nanoscale" lab. Our research is focused on the design and production of complex miniature structures that can absorb sunlight and use the energy within it to generate clean fuel or to purify contaminated water. We are doing our best to harness chemistry, physics, and engineering to make our world slightly better. When I am not researching, I can be found spending time with my partner Omri, and our three kids, Shalev, Dolev, and Shani. I also enjoy arts and crafts, hiking, and reading. *lilac@atechnion.ac.il 